\title{
Dimensions of the scientific collaboration and its contribution to the academic research groups' scientific quality
}

\author{
Helga Bermeo ${ }^{(1,3)}$, Ernesto De los Reyes ${ }^{(1)}$ and Tomas Bonavia ${ }^{(2)}$ \\ (1) Institute of Innovation and Knowledge Management - INGENIO (CSIC-UPV), Valencia - Spain \\ (2) University of Valencia, Valencia - Spain \\ (3) Universidad de Ibagué, Grupo NEVADO, Ibagué - Colombia. \\ Contact person \\ Bermeo, Helga P., helga.bermeo@unibague.edu.co. Phone: 578750011
}

Key Words: Scientific collaboration, Research performance, Academic groups

\begin{abstract}
This article analyzes, under several dimensions, if collaboration contributes to the production of high quality scientific results. It examines the proportion of scientific quality (measured by impact and relevance) gained by ISI publications considering the presence of a particular form of collaboration. As an application case, this paper offers a micro-level analysis of the academic research groups (ARGs) of a technical university. Results indicate that there are positive and significant benefits in scientific quality, received by ARGs as product of the international and inter-sector collaboration, and in a broader sense, from the presence of the inter-institutional collaboration.
\end{abstract}

\section{Introduction}

The growing emphasis on research activities oriented to specific problems has required more than a change in the concept of 'the research object', a change in the 'ways of doing research'. This has required going beyond the disciplinary, institutional and geographical boundaries, for the study and solution of these problems by the scientific community. Teamworking and collaboration have become the vehicles for the integration of knowledge, efforts and capabilities for the research processes.

In recent decades collaborative research has grown significantly. It has been considered as one of the main characteristics of modern science as well as the new way of production of knowledge (Gibbons et al., 1994; Hagedoorn, 2000). Trends in scientific collaboration are becoming increasingly involved with the growth of co-authored publications, with the division of the scientific work required in large experimental teams and with the formation of multidisciplinary teams in research organizations, whose members usually come from different geographic regions and belong to several economic sectors (Beaver, 2001; Jeffrey, 2003; Glänzel \& Schubert, 2005).

Scientific collaboration is considered as a mean for research advancement, as well as a mechanism to enhance visibility and, in some cases, researchers' productivity. As a strategy 
Bermeo, H.; De los Reyes, E. y Bonavia, T. (2009). Dimensions of scientific collaboration and its contribution to the academic research groups's scientific quality. Research Evaluation, 18 (4), 301-311.

towards achieving research excellence, collaboration is not simply an alternative suitable to be chosen among other types of work; this, by itself is inherented as behaviour in the path towards competitiveness wherever scientific research is conducted (Rogers, 2000). The active trend towards cooperation is a phenomenon explained not only by the increasing necessity of sharing resources, skills and competences involving the desire of making significant contributions to society, but also, by the increasing facilities offered by the information and communication technologies, which minimize the potential geographical, temporal and cultural barriers between the collaborating parts.

In this sense, Bozeman \& Corley (2004) found that some of the most frequent reasons for collaborative research are: access to expertise, access to unavailable equipment or resources; encouragement of multidisciplinary growth, improvement of the capability to get funds; prestige or visibility achievement; tacit knowledge acquirement about techniques; aggregation of knowledge for managing large and complex problems; productivity, education and training improvement of students and young researchers, increasing science specialization, or simply the pleasure of working with 'colleagues'.

This article is mainly focused at the micro-level analysis of the scientific collaboration's benefits, which is understood as part of a researchers' strategy to increase their performance level in R\&D. In particular, we analyze the gains in quality of their scientific production, using the academic research groups of a technical university, as an empirical case. This paper is organized as follows: section 2 presents the concepts and theoretical foundations for a better understanding of the dynamics, strengths and strategies of scientific collaboration from and with the university; section 3 covers a brief literature review of methods used to measure scientific collaboration and their application into the university context; section 4 the results of the analyzed empirical case are discussed, including data and methodology; finally, section 5 deals with discussion and limitations of the study, and section 6 presents the conclusions of the paper.

\section{Theoretical framework}

The word collaboration is interchangeably and indistinctly used with other terms such as cooperation and alliances. Collaboration can occur at the level of individuals or institutions. In general, collaboration between organizations is defined as a reciprocal and well defined relationship established to achieve common goals, while collaboration between individuals is generally defined as a process of shared creation, where individuals interact to create and share knowledge that none of them previously possessed or could have developed him/herself. Regardless of the level at which it is carried out, it is clear that collaboration is a process based on knowledge sharing as well as achievement of common goals (Belkhodja \& Laundry, 2005). 
Bermeo, H.; De los Reyes, E. y Bonavia, T. (2009). Dimensions of scientific collaboration and its contribution to the academic research groups's scientific quality. Research Evaluation, 18 (4), 301-311.

For Smith \& Katz (2000), collaboration in the research context involves several concrete and symbolic meanings. Collaboration is frequently linked to formal and informal research alliances and networks. In practice, the term alliance is understood as partnerships based on a formal and legal body, established by two or more autonomous allies, with the objective of achieving significant or symbolic goals. In the university environment, the term collaboration involves a wide range of possibilities, ranging from teaching, student participation, lifelong learning, as well as commercialization of research and intellectual property, technology transfer, consultancy and research. Research collaboration in this context is understood as the $R \& D$ activities established by the academic research units or their members with other peers, to share and gain knowledge, to increase technological capacities and to reach common goals related with scientific and technological fields.

Given the importance that collaboration in research has demonstrated, it is natural that theorists of different disciplines are interested on explaining this phenomenon. On one hand, there are works that supported on macroeconomic theories propose models that explain the phenomenon by which, the global scientific collaboration has emerged as an indispensable work of the scientific and technological community for the generation and maintenance of current knowledge-based economies. On the other hand, there are works that are focused on the literature of scientific fields, such as the Organizational theory, Games theory and Management, in the analysis of the behaviour adopted by the parties linked in the collaborative activities and alliances in R\&D.

For Hemphill \& Vonortas (2003), the different theoretical approaches that have been proposed to understand the collaborative processes can be summarized in two schools of thought: costs-based partnerships and strategies-based partnerships. The first school is supported on Game theory to analyze the behaviour of the parties involved, and the influence of the transaction costs and the power dominance of a part in the success and maintenance of alliances (Kogut, 1988). Under this approach, the transaction costs of partnerships vary among organizations, because of the differences in their goals, skills and strategies to ensure the access to capacities they do not possess. This makes organizations show different behaviors, some decide to internalize the alliances while others, or under other circumstances, decide to externalize them. In the case of research partnerships, the transaction costs can be high, for example in high-tech sectors such as biotechnology, information technology and advanced materials, which are sectors with a high market expectation as well as a high technological uncertainty (Hagedoorn, Links \& Vonortas, 2000).

The second school is based on the Organizational and Management theories, and focuses on analyzing the strategic incentives for collaboration. The Organizational theory suggests that the incentive for collaboration is the formation of strategic networks that enabling the parties to gain or maintain competitive advantages designed to take advantage of the value joint creation opportunities (Ebers \& Jarillo, 1998). Management theories propose that what 
Bermeo, H.; De los Reyes, E. y Bonavia, T. (2009). Dimensions of scientific collaboration and its contribution to the academic research groups's scientific quality. Research Evaluation, 18 (4), 301-311.

encourages organizations to collaborate, is to appropriate those strategic choices that best fit their own capacities with the opportunities offered by the environment (see Bowman \& Hurry, 1993). Through partnerships, organization collaborating with each other, they develop business links based on experience and trust, complement they own capacities and acquire new skills and knowledge through the organizational learning, increasing its visibility in its market segment (for further review see Hemphill \& Vonortas, 2003).

\subsection{Collaboration in the context of knowledge society}

Two of the main theoretical approaches that consider scientific collaboration as one of the scientific and technological systems' characteristics in the current era of knowledge, are the following: the new mode of knowledge production or 'Mode-2' (Gibbons et al. 1994), and the 'Triple Helix' model (Etzkowitz \& Leydesdorff, 2000). Under the approach of the new mode of knowledge production or 'Mode-2', research is the product of knowledge created into a practical context, involving multidisciplinary and heterogeneous groups, whose results are quantifiable in economic and social terms (Dodgson, 1999). Under the Triple Helix model, innovation occurs in a not preconfigured sequence, there are only particular arrangements of participants - mainly from universities, industries and governments-, who under changing strategies, actions and projects, continuously reorganize existing infrastructures in order to reach/approximate to the proposed goals (Etzkowitz \& Leydesdorff, 2000).

Analyzing these theoretical approaches together, it is possible to realize that, in addition to offer a broad perspective of the innovation process, they reflect the emerging dynamic and growing importance of knowledge for the economy and the society. In the specific case of the university, its growing integration with the environment, has influenced and affected its collaboration practices. A good example of this influence is the one derived from government's policies in scientific \& technological matters, where the support and funding policy for university research is each time more conditioned to the presence of multidisciplinary and multi-institutional teams involving industry co-participation.

In spite of the undeniable advantages of establishing extra-institutional partnerships, this is a task that represents major challenges for the university. The first challenge is to manage the strain caused by the necessity of fulfilling the agreed plans and results; which in many cases involves the establishment of effective information, communication and control systems, and even can lead to the creation of additional alliances to achieve the required skills and knowledge. The second challenge is related with the university's necessity of being efficient in the use of resources and effectiveness in the achievement of desired results. To fulfill this, one of the key aspects is to establish research partnerships that enable them to achieve economies of scale, avoiding, reducing or eliminating unnecessary costs at the same time. 
The final version of this paper was published in:

Bermeo, H.; De los Reyes, E. y Bonavia, T. (2009). Dimensions of scientific collaboration and its contribution to the academic research groups's scientific quality. Research Evaluation, 18 (4), 301-311.

\subsection{Collaboration in the group context}

A group in general can be understood as a set of people working together to produce outcomes in which they are mutually involved. Whiting the groups usually there are shared goals and common interests, interactions between the group members, as well as between them and members of other groups, in order to share knowledge, experience and skills. When a group is formed by individuals having diverse skills and experiences, there is a set of tangible and intangible assets that support their work and the achievement of their objectives. Among the intangible assets of a group it is possible to find the so called intellectual capital, which is part of its social or relational capital. Social relationships and cooperation activities are essential in the creation of the groups' intellectual and social capital, and beyond that, to increase their capabilities for the generation of new knowledge. Given the presence of social capital, groups are willing to share information and knowledge, and therefore, the intragroups and inter-groups collaboration actions are easier for them (Luo, 2005).

Two key features are highlighted in the generation of social capital and reflect the dynamics of group collaboration. Firstly, the presence of leaders showing a vast social capital, in fact this can be positive for others in the group, but it may imply an excessive centralization of knowledge as well as close cooperative ties. Secondly, the presence of rules supporting the creation of the group, because it is formed through the interaction between members, where power relations and responsibilities among the members are present; in this situation, there is more 'motivation' to share capital. It is not the same for a group only formed by collective intra-groups actions, which is dominated by links of friendship and social obligations; this could have a valuable social capital, without being reflected on its improvement.

Pursuing their objectives, groups tend to be born, grow and die, according to a dynamic that viewed in detail, reveals collaboration patterns in the practical work. Recent study about work teams (Guimerá et al., 2005) shows that patterns of shaping groups aim to satisfy two purposes: creating groups large enough to enable tasks specialization as well as knowledge complement and the division of labor; but at the same time, creating groups small enough to avoid cost overruns due to problems of coordination and/or inefficiency.

\subsection{Scientific collaboration and performance in research activities}

At this point, the question is the following: What are the effects of collaboration in the groups' performance? Are these effects related with the presence of a specific type of collaboration? The growing interest in scientific collaboration lies on the fact that it is considered essential to the working groups' efficiency and good operation. Its positive effect on the groups' performance is connected with the effect of other groups' key features such as: diversity of skills, task's identity and significance, autonomy and feedback (Abbot, Boyd \& Miles, 2006). 
Bermeo, H.; De los Reyes, E. y Bonavia, T. (2009). Dimensions of scientific collaboration and its contribution to the academic research groups's scientific quality. Research Evaluation, 18 (4), 301-311.

The study of the relationship between collaboration practices of a group and its level of performance is a matter of the academics interest from diverse areas of knowledge such as Psychology, Management and Economics. In the context of research communities, Guimerá and colleagues relate both the collaboration level and groups' performance with the patterns emerged from their co-authored publications. Considering the fact that research groups are embedded in large knowledge networks, these authors find that research teams having a wide range of partners have more opportunities to being fed from several knowledge sources as well as producing more relevant publications (Guimerá et al., 2004). The results of this study suggest two important aspects: a) the highest-performing groups are those having a high number of senior collaborators, and b) groups publishing in high-impact journals form large and important knowledge networks, as well as, show more efficiency when using resources coming from 'invisible' partners linked to the network.

At the university micro-level analysis, it is important to mention the studies of Melin (2000) and Bozeman \& Lee (2003). Melin focuses on the analysis of collaboration between scientists. Using the results of his study, the author finds arguments to conclude that it is a phenomenon that occurs depending on some way in the following factors: the reasons that motive it, the ways in which it occurs and the benefits it generates for scientists. Bozeman \& Lee, in a more explicit manner, demonstrate the positive effects of research collaboration on the scientists' productivity, under the presence of structural environmental variables such as: gender, academic status, nationality and collaboration strategies.

\section{Measures of scientific collaboration: a view from previous empirical evidence}

Beaver (2001) in his reflection about the past, present and future of scientific collaboration, he finds that there is a 'global' presence of academics dedicated to the systematic study of this phenomenon, making an effort to extend information and knowledge about the structure and dynamics of collaboration at all levels. According to this author, the continuing and growing interest of the scientific community is a natural response to the constant variation in the collaboration practices resulting from changes in the organization of research activities in the creation, transfer and appropriation of knowledge, under the current dynamics of globalization and internationalization.

Literature about collaboration in $\mathrm{R} \& \mathrm{D}$ is broad, mainly that involving the following three dimensions of study: disciplinary, sector and geographic (see Table 1). These studies were addressed to define each way of the characteristics, motivations and benefits of partnership, with the aim of reaching a better understanding of its dynamics and effects. Table 1 shows that these studies related with the analysis of scientific collaboration, are also distinguished by the scope of the study: at macro-level (countries), mezzo-level (institutions, networks) or micro-level (institutes, groups, researchers). Recent studies at micro-level are focused on 
Bermeo, H.; De los Reyes, E. y Bonavia, T. (2009). Dimensions of scientific collaboration and its contribution to the academic research groups's scientific quality. Research Evaluation, 18 (4), 301-311.

different aspects of scientific collaboration, some examples are the following: the analysis of the benefits of geographical proximity between partners (Havemann et al., 2006); the exploration of the strength and shape of the groups' composition and their performance level (Guimerá et. al, 2005); the recognition of collaboration strategies and their implications on the researchers' scientific, technical and human capital; or the impact analysis of co-authored publications on researchers' performance (Basu \& Aggarwal, 2001; Bozeman \& Lee, 2003).

One of the most common ways of measuring collaboration, and the most widely documented in the scientific literature is the bibliometric analysis based on co-authored articles published in the ISI journal index (Glänzel \& Schubert, 2004). The widespread use of this way of measurement is explained not only by the belief that publications are one of the main outcome of research, but also because the most relevant publications are recorded in databases that can be purchased and easily processed by researchers. Using co-authorship, it is possible to measure the scientific collaboration through indicators expressing the quantity, quality or the impact generated by its occurrence.

Table 1. Selected references analyzing the dimensions of the scientific collaboration

\begin{tabular}{|c|c|c|}
\hline \multicolumn{2}{|c|}{ Dimension of the study } & \multirow{2}{*}{ Study field } \\
\hline Main dimension & Sub-dimension & \\
\hline \multirow[t]{2}{*}{ Disciplinary } & Inter-disciplinary & $\begin{array}{l}\text { Interdisciplinary research analysis in French laboratories } \\
\text { (Sigogneau et al., 2005). }\end{array}$ \\
\hline & Intra-disciplinary & $\begin{array}{l}\text { Interaction links between Australian research networks } \\
\text { (Rigby, 2005). }\end{array}$ \\
\hline \multirow[t]{2}{*}{ Sector } & Inter-sector & $\begin{array}{l}\text { Cooperation models industry-university in Belgium } \\
\text { (Veugelers \& Cassiman, 2005). }\end{array}$ \\
\hline & Intra-sector & $\begin{array}{l}\text { Academic research networks analysis (Lowrie \& } \\
\text { McKnight, 2004). }\end{array}$ \\
\hline \multirow[t]{2}{*}{ Geographic } & International & $\begin{array}{l}\text { Comparative analysis in several countries, of their } \\
\text { international/national collaborated publications (Glänzel \& } \\
\text { Schubert, 2005). }\end{array}$ \\
\hline & Intra-national & $\begin{array}{l}\text { The interaction between immunology research institutes in } \\
\text { Germany, due to its geographical location (Havemann et } \\
\text { al., 2006). }\end{array}$ \\
\hline
\end{tabular}

\section{Empirical evidence}

The analysis presented in this paper is supported by the study case of 135 Academic Research Groups (ARG) of the Universidad Politécnica de Valencia (UPV), linked to R\&D activities of Basic Sciences (42\%) and Technical Sciences (58\%). This sample $(\mathrm{g}=135)$ was composed by 
Bermeo, H.; De los Reyes, E. y Bonavia, T. (2009). Dimensions of scientific collaboration and its contribution to the academic research groups' scientific quality. Research Evaluation, 18 (4), 301-311.

$30 \%$ of small groups (with less than two full time equivalent researchers involved), and $70 \%$ of big groups (with a maximum size of a group with 51 full time equivalent researchers involved). In terms of age, $18 \%$ were emergent groups (with less than 3 years old) and $82 \%$ were consolidated groups (with a maximum of 10 years old). About the groups' scientific output, particularity that linked to ISI articles published, the average of the groups during the analyzed period was around 14 articles in a range between [1,212] articles, being the average higher in groups of Technical Sciences (15 articles) than in groups of Basic Sciences (13 articles). |

The Groups' ISI publications generated during the period 2003-2005, in total 1.744 articles, were used to prove that scientific collaboration has positive effects on the groups' performance, particularly on the quality improvement of their scientific production; and that these effects are related with the presence of specific ways of collaboration, especially the inter-institutional one, because of the participation of coauthors coming from a non academic sector (inter-sector collaboration) and/or coauthors from a non near geographical region (international collaboration).

\subsection{Methodological issues}

In the articles, the following three dimensions and criteria where considered to assure distinction between the collaboration types:

- Institutional dimension: Intra-UPV (UPV as the only institutional address for all authors), Extra-UPV (UPV and other institutions related with the authors).

- Sector dimension: Academic (UPV and other academic institutions), scientifictechnological (UPV and at least one non academic institution but belonging to the scientific and technological sector, such as technology centers), Entrepreneurial (UPV and at least one institution belonging to the business sector).

- Geographical dimension: Local (UPV and one or more institutions located in the same city where UPV is located, Valencia), National (UPV and at least one institution from another region of Spain), International (UPV and at least one institution located in a country apart from Spain).

The scientific quality is measured using two indicators: impact (IMP) and relevance (REL). The impact is measured by the impact factor of the journals where the articles were published. The relevance (REL) is measured by the number of citations of the articles, published per year. Here, both measurements, the journals' impact factor and the articles' citations are taken from the ISI data bases 2001-2007. 
Bermeo, H.; De los Reyes, E. y Bonavia, T. (2009). Dimensions of scientific collaboration and its contribution to the academic research groups's scientific quality. Research Evaluation, 18 (4), 301-311.

Finally, the bibliometric index of gain (IG) proposed by Basu and Aggarwal (2001) is used to measure the benefits obtained when scientific collaboration is present in the ISI articles. Especially we analyze the presence of the following types of collaboration: Inter-institutional Scientific Collaboration (IISC), International Scientific Collaboration (INTSC) and Intersector Scientific Collaboration (INSSC). The index takes into account the proportion of coauthored articles in each type of collaboration and measures their differences and their proportional quality gains. Just as an example, here the formula used to estimate the IG in scientific impact produced by the presence of international scientific collaboration (IGIMP_INTSC):

where,

$$
\mathrm{IGIMP} \_\mathrm{INTSC}=\left(\frac{I M P_{-} I S I_{-} I N T}{Q_{-} I S I} * 100\right)-\left(\frac{A R T_{-} I S I_{-} I N T}{A R T_{-} I S I} * 100\right)
$$
IMP_ISI_INT:
Cumulative impact factor of ISI articles involving international collaboration
Q_ISI:
Cumulative impact factor of all ISI articles
ART_ISI_INT: Number of ISI articles involving international collaboration
ART_ISI:
Number of ISI articles

With the aim of achieving a better analysis, group-level areas were divided into two categories according to the total number of ISI articles (ART_ISI) produced in the period. The subcategories are established according to whether they are above or below the median value of the variable ART_ISI calculated for each scientific area (Basic and Technical). For example, in basic sciences, $50 \%$ of the groups were categorized as a low scientific level and the other $50 \%$ as a high scientific level. This additional distinction between ARGs is made to assess whether those groups that are intensive in scientific research differ from the less intensive ones, regarding the benefits received from scientific collaboration.

\subsection{Results}

After reviewing the numbers of co-authors of the ISI articles published by the ARG selected for this study, it was found that the most frequent number of co-authors per article is between 2-4 (see Figure 1), and the most usual situation is that maximum of two co-authors per article belong to UPV. 
Bermeo, H.; De los Reyes, E. y Bonavia, T. (2009). Dimensions of scientific collaboration and its contribution to the academic research groups's scientific quality. Research Evaluation, 18 (4), 301-311.

Figure 1. Histogram of the number of co-authors in ISI Articles

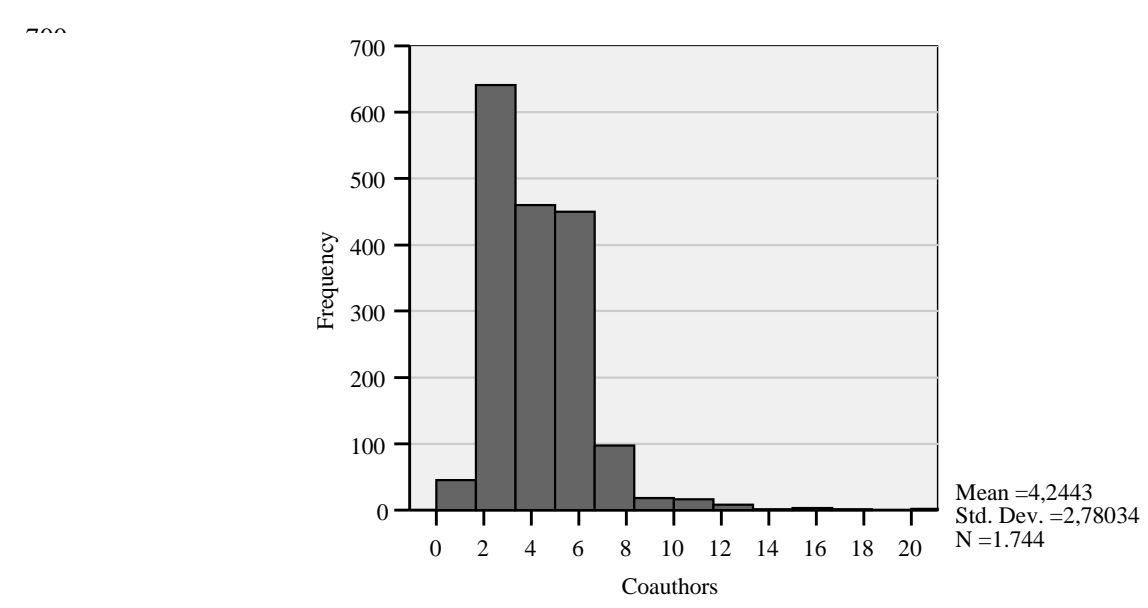

Once the types of collaboration in each publication were identified, results reveal that on the base of the institutional dimension, $73 \%$ of the articles are collaborated with co-authors from outside UPV. Regarding to the geographical dimension, $25 \%$ of the articles include international co-authors and $63 \%$ of the articles include only local authors (Valencia). Finally, on the base of the sector dimension, about $84 \%$ of the articles show only academic co-authors and the remaining ones, correspond to articles co-authored by researchers coming from institutions linked to other economic sectors, such as research institutes or private companies.

The first evidence of the benefits coming from the scientific collaboration arises with the comparison of the average values of quality estimated by each type of collaboration. Table 2 shows that on the base of institutional dimension, the impact and relevance levels tend to be high if the articles are coauthored with researchers Extra-UPV. The detailed results reveal that is the inter-institutional collaboration, mainly identified by international collaboration and/or inter-sector collaboration, which offers a higher opportunity to the articles to be published in journals with high scientific impact.

This initial evidence about the benefits of the inter-institutional collaboration is, in some way, confirmed with the results of the statistical analysis. Table 3 shows the average values of the IG in scientific impact (IGIMP) and scientific relevance (IGREL), obtained by the groups in each category of analysis. In almost all the cases, the average values of the IG are positive, with the exception of the groups with low scientific level working in Basis Sciences, which in average report loses in scientific relevance, when their articles have inter-sector collaboration. 
Bermeo, H.; De los Reyes, E. y Bonavia, T. (2009). Dimensions of scientific collaboration and its contribution to the academic research groups's scientific quality. Research Evaluation, 18 (4), 301-311.

Tabla 2. Average quality of the ISI articles by collaboration types

\begin{tabular}{|c|c|c|c|c|c|c|c|c|}
\hline \multirow{3}{*}{$\begin{array}{l}\text { Geographical } \\
\text { Dimension }\end{array}$} & \multirow{3}{*}{$\begin{array}{l}\text { Sector } \\
\text { Dimension }\end{array}$} & \multirow{3}{*}{$\begin{array}{c}\text { Articles } \\
\text { analyzed } \\
\text { (a) } \\
\text { (a) }\end{array}$} & \multicolumn{6}{|c|}{ Institutional Dimension } \\
\hline & & & \multicolumn{2}{|c|}{$\begin{array}{c}\text { IntraUPV } \\
(\mathrm{a}=458)\end{array}$} & \multicolumn{2}{|c|}{$\begin{array}{l}\text { ExtraUPV } \\
(a=1.288)\end{array}$} & \multicolumn{2}{|c|}{$\begin{array}{c}\text { Total } \\
(a=1.744)\end{array}$} \\
\hline & & & IMP & REL & IMP & REL & IMP & REL \\
\hline \multirow[t]{4}{*}{ Local } & Academic & $(1.027)$ & 1,24 & 0,57 & 1,59 & 0,68 & 1,44 & 0,63 \\
\hline & Scient -Tech. & $(60)$ & & & 1,58 & 0,76 & 1,58 & 0,76 \\
\hline & Entreprenurial & (21) & & & 1,63 & 0,51 & 1,63 & 0,51 \\
\hline & Total & (1.108) & 1,24 & 0,57 & 1,59 & 0,68 & 1,45 & 0,64 \\
\hline \multirow[t]{4}{*}{ National } & Academic & $(150)$ & & & 1,34 & 0,58 & 1,34 & 0,58 \\
\hline & Scient -Tech, & (39) & & & 2,36 & 1,29 & 2,36 & 1,29 \\
\hline & Entrepreneurial & (13) & & & 1,31 & 0,22 & 1,31 & 0,22 \\
\hline & Total & $(202)$ & & & 1,54 & 0,70 & 1,54 & 0,70 \\
\hline \multirow[t]{4}{*}{ International } & Academic & (311) & & & 1,65 & 0,81 & 1,65 & 0,81 \\
\hline & Scient -Tech, & (94) & & & 2,03 & 0,78 & 2,03 & 0,78 \\
\hline & Entrepreneurial & (29) & & & 2,95 & 1,54 & 2,95 & 1,54 \\
\hline & Total & (434) & & & 1,82 & 0,86 & 1,82 & 0,86 \\
\hline \multirow[t]{4}{*}{ Total } & Academic & $(1.488)$ & 1,24 & 0,57 & 1,58 & 0,71 & 1,47 & 0,66 \\
\hline & Scient -Tech, & (193) & & & 1,96 & 0,88 & 1,96 & 0,88 \\
\hline & Entrepreneurial & (63) & & & 2,17 & 0,92 & 2,17 & 0,92 \\
\hline & Total & $(1.744)$ & 1,24 & 0,57 & 1,66 & 0,74 & 1,55 & 0,70 \\
\hline
\end{tabular}

Source: Calculated with the information from ISI data bases (www,isiknowledge,org)

In complementary way, we use the t-test to contrast the hypothesis that the average gain in each case of combination (scientific level and scientific area) is different from zero; but excluding those atypical cases in order to have more statistical validity. The $t$-test results, marked with underlined mean values in Table 4, reveal that considering the categories of the analysis, not all the average values can be considered statistically different from zero. If we take into account all the groups included in the study, the gains are positive and in general, there are more ARG with gain over zero, as a product of inter-institution collaboration in the production of their scientific publications, especially if the collaborators are international.

Source: Calculations based on data obtained from the ISI, 2007; $a^{\prime}=1.918$ articles (This number is higher than the original sample -a:1.744 articles-, because there are articles produced by two o more coauthors coming from different $A R G)$. 
The final version of this paper was published in:

Bermeo, H.; De los Reyes, E. y Bonavia, T. (2009). Dimensions of scientific collaboration and its contribution to the academic research groups' scientific quality. Research Evaluation, 18 (4), 301-311.

Table 3. Descriptive statistics of Index of Gain (IG) given by the presence of Scientific Collaboration

\begin{tabular}{|c|c|c|c|c|c|c|c|c|c|c|c|c|}
\hline \multirow{3}{*}{$\begin{array}{l}\text { Gains due to scientific } \\
\text { collaboration }\end{array}$} & \multirow{3}{*}{ Variable } & \multirow[b]{3}{*}{$\begin{array}{l}\text { No. of } \\
\text { ARG } \\
(\mathrm{g})\end{array}$} & \multirow{3}{*}{ Statistics } & \multicolumn{9}{|c|}{ Scientific Area } \\
\hline & & & & \multicolumn{3}{|c|}{$\begin{array}{c}\text { Basic Science } \\
(\mathrm{g}=55 \mathrm{ARG})\end{array}$} & \multicolumn{3}{|c|}{$\begin{array}{c}\text { Technical Science } \\
(\mathrm{g}=80 \mathrm{ARG})\end{array}$} & \multicolumn{3}{|c|}{$\begin{array}{c}\text { Total } \\
(\mathrm{g}=135 \mathrm{ARG})\end{array}$} \\
\hline & & & & $\begin{array}{c}\text { Low } \\
\text { scientific } \\
\text { level }\end{array}$ & $\begin{array}{c}\text { High } \\
\text { scientific } \\
\text { level }\end{array}$ & Total & $\begin{array}{c}\text { Low } \\
\text { scientific } \\
\text { level }\end{array}$ & $\begin{array}{c}\text { High } \\
\text { scientific } \\
\text { level }\end{array}$ & Total & $\begin{array}{c}\text { Low } \\
\text { scientific } \\
\text { level }\end{array}$ & $\begin{array}{c}\text { High } \\
\text { scientific } \\
\text { level } \\
\end{array}$ & Total \\
\hline \multirow{3}{*}{$\begin{array}{l}\text { IG in scientific impact due to } \\
\text { International collaboration }\end{array}$} & \multirow{3}{*}{ IGIMP_INT } & \multirow{3}{*}{88} & $95 \%$ CIL & -6.66 & -2.26 & -1.89 & -1.73 & -8.60 & -0.16 & -1.64 & 0.21 & 0.45 \\
\hline & & & Mean & 0.21 & 2.66 & 1.97 & 3.01 & 4.19 & 2.64 & 2.04 & 2.63 & 2.44 \\
\hline & & & $95 \% \mathrm{CIH}$ & 7.10 & 7.59 & 5.82 & 7.75 & 29.11 & 5.46 & 5.73 & 5.06 & 4.43 \\
\hline \multirow{3}{*}{$\begin{array}{l}\text { IG in scientific relevance due to } \\
\text { International collaboration }\end{array}$} & \multirow{3}{*}{ IGREL_INT } & \multirow{3}{*}{88} & $95 \% \mathrm{CIL}$ & -14.52 & -2.39 & -2.09 & -4.03 & -33.33 & -33.33 & -3.23 & -0.86 & 0.53 \\
\hline & & & Mean & 1.93 & 8.28 & 6.47 & 8.14 & 3.74 & 5.12 & 6.00 & 5.49 & 5.66 \\
\hline & & & $95 \% \mathrm{CIH}$ & 18.39 & 18.97 & 15.03 & 20.31 & 90.00 & 90.00 & 15.23 & 11.84 & 10.78 \\
\hline \multirow{3}{*}{$\begin{array}{l}\text { IG in scientific impact due to } \\
\text { Inter-sector collaboration }\end{array}$} & \multirow{3}{*}{ IGIMP_INS } & \multirow{3}{*}{81} & $95 \%$ CIL & -3.58 & -4.21 & -2.69 & -1.51 & -8.81 & -4.44 & -0.75 & -1.00 & 0.04 \\
\hline & & & Mean & 0.72 & 0.74 & 0.74 & 6.26 & 5.04 & 3.00 & 3.60 & 1.82 & 2.37 \\
\hline & & & $95 \% \mathrm{CIH}$ & 5.03 & 5.69 & 4.16 & 14.04 & 36.16 & 10.44 & 7.97 & 4.65 & 4.70 \\
\hline \multirow{3}{*}{$\begin{array}{l}\text { IG in scientific relevance due to } \\
\text { Inter-sector collaboration }\end{array}$} & \multirow{3}{*}{ IGREL_INS } & \multirow{3}{*}{81} & $95 \% \mathrm{CIL}$ & -17.58 & -6.47 & -6.95 & 2.74 & -50.00 & 4.63 & -1.96 & -1.66 & 0.45 \\
\hline & & & Mean & -2.91 & 0.92 & -0.39 & 31.45 & 17.37 & 14.78 & 14.95 & 2.44 & 6.31 \\
\hline & & & $95 \% \mathrm{CIH}$ & 11.75 & 8.32 & 6.17 & 60.15 & 87.50 & 24.93 & 31.87 & 6.55 & 12.16 \\
\hline \multirow{3}{*}{$\begin{array}{l}\text { IG in scientific impact due to } \\
\text { inter-institutional collaboration }\end{array}$} & \multirow{3}{*}{ IGIMP_ITT } & \multirow{3}{*}{125} & $95 \%$ CIL & -4.65 & 0.00 & -1.08 & -0.28 & -7.72 & -0.24 & -0.66 & -0.02 & 0.34 \\
\hline & & & Mean & 0.59 & 2.80 & 1.74 & 2.99 & 3.48 & 2.17 & 1.97 & 1.86 & 1.92 \\
\hline & & & $95 \% \mathrm{CIH}$ & 5.85 & 5.60 & 4.57 & 5.70 & 25.00 & 4.58 & 4.61 & 3.74 & 3.49 \\
\hline \multirow{3}{*}{$\begin{array}{l}\text { IG in scientific relevance due to } \\
\text { Inter-institutional collaboration }\end{array}$} & \multirow{3}{*}{ IGREL_ITT } & \multirow{3}{*}{125} & $95 \%$ CIL & -1.59 & -7.32 & -2.15 & -3.86 & -58.33 & -3.74 & -0.73 & -4.38 & -1.10 \\
\hline & & & Mean & 5.58 & 1.20 & 3.31 & 3.22 & 4.05 & 2.90 & 4.22 & 1.07 & 2.56 \\
\hline & & & $95 \% \mathrm{CIH}$ & 12.75 & 9.74 & 8.76 & 10.32 & 62.50 & 9.54 & 9.18 & 6.51 & 6.22 \\
\hline
\end{tabular}


Table 4. The $t$-test results of Indexes of Gains (IG) excluding atypical cases, $H_{0}: I G=0$ *

\begin{tabular}{|c|c|c|c|c|c|c|c|c|c|c|}
\hline \multirow[b]{2}{*}{$\begin{array}{c}\text { Index of } \\
\text { Gains }\end{array}$} & \multicolumn{3}{|c|}{ Low scientific level } & \multicolumn{3}{|c|}{ High scientific level } & \multicolumn{3}{|c|}{ Total } & \multirow[b]{2}{*}{$\begin{array}{l}\text { ARG in } \\
\text { sample }\end{array}$} \\
\hline & $\begin{array}{l}95 \% \\
\text { CIL }\end{array}$ & Mean & $\begin{array}{l}95 \% \\
\text { CIL }\end{array}$ & $\begin{array}{l}95 \% \\
\text { CIL } \\
\end{array}$ & Mean & $\begin{array}{l}95 \% \\
\text { CIL }\end{array}$ & $\begin{array}{l}95 \% \\
\text { CIL }\end{array}$ & Mean & $\begin{array}{l}95 \% \\
\text { CIL }\end{array}$ & \\
\hline IGIMP_INT & -2.61 & 0.32 & 3.26 & -0.41 & 1.09 & 3.88 & -0.22 & 1.52 & 3.27 & 85 \\
\hline IGREL_INT & -5.59 & 0.62 & 9.52 & -5.03 & 0.85 & 4.16 & -2.99 & 1.01 & 5.01 & 79 \\
\hline IGIMP_INS & -1.38 & 2.5 & 6.38 & -2.53 & -0.89 & 0.75 & -1.05 & 0.57 & 2.21 & 72 \\
\hline IGREL_INS & -1.55 & 14.7 & 30.95 & -1.66 & 2.44 & 6.56 & -2.30 & 0.48 & 4.82 & 72 \\
\hline IGIMP_ITT & 0.64 & $\underline{2.78}$ & 4.91 & -0.16 & 0.76 & 3.15 & 0.37 & $\underline{1.67}$ & 2.97 & 119 \\
\hline IGREL_ITT & 0.43 & $\underline{4.37}$ & 8.31 & -1.12 & 0.15 & 7.12 & 0.66 & $\underline{3.52}$ & 6.39 & 113 \\
\hline
\end{tabular}

* Numbers underlined represent bilateral significance of $t$-test at $5 \%$.

A more detailed analysis of the inter-institutional collaboration gains generated by the presence of International Collaborators (CBINT) or Inter-sector Collaborators (CBINS) is discussed as the following.

\section{- Gains by the presence of International Scientific Collaboration - INTSC}

As an example, Figures $2 \mathrm{a}$ and $\mathrm{b}$ present the groups' gains in quality versus the percentage of articles involving international collaborators, for each category (a high and low scientific level) and every scientific area (Basic Sciences and Technical Sciences). Results suggest that this form of collaboration plays a role at the moment of estimating the gains in scientific quality from the groups (there are benefits if the Index of Gains IG>0).

Gains by INTSC for groups with a high scientific level are more evident in the groups belonging to Technical Sciences than in the groups from Basic Sciences, although there is not a clear evidence of a direct relationship between the extension of the collaboration and the gains. It should be emphasized that for Basic Science groups with a high scientific level, the extension of the partnership is not more than $50 \%$, and in the case of the Technical Science groups, the extension is about $70 \%$. Something different happens with the groups with a low scientific level: while in the Basic Science groups the extension of collaboration reaches $95 \%$, in the Technical Science groups the extension does not exceed $60 \%$,

International collaboration is also valuated for its contribution to greater citation of the ISI articles. The analysis in this sense reveals that there are more benefits for groups with a high scientific level of Technical Sciences than of Basic Sciences; however there are not clear evidences about a direct relationship between the extension of the collaboration and the gains on scientific impact.

With the general comparison of the proportion of groups obtaining benefits from the international collaboration, independently by their scientific level, it is found that Technical Science groups are more likely to achieve benefits than Basic Science groups (55\% to 48\%, respectively). 
Figure 2. Scatter plot between Gains in Scientific Impact and International Scientific Collaboration $a=434$ articles, $g=88$ ARG

a) Basic Sciences Area

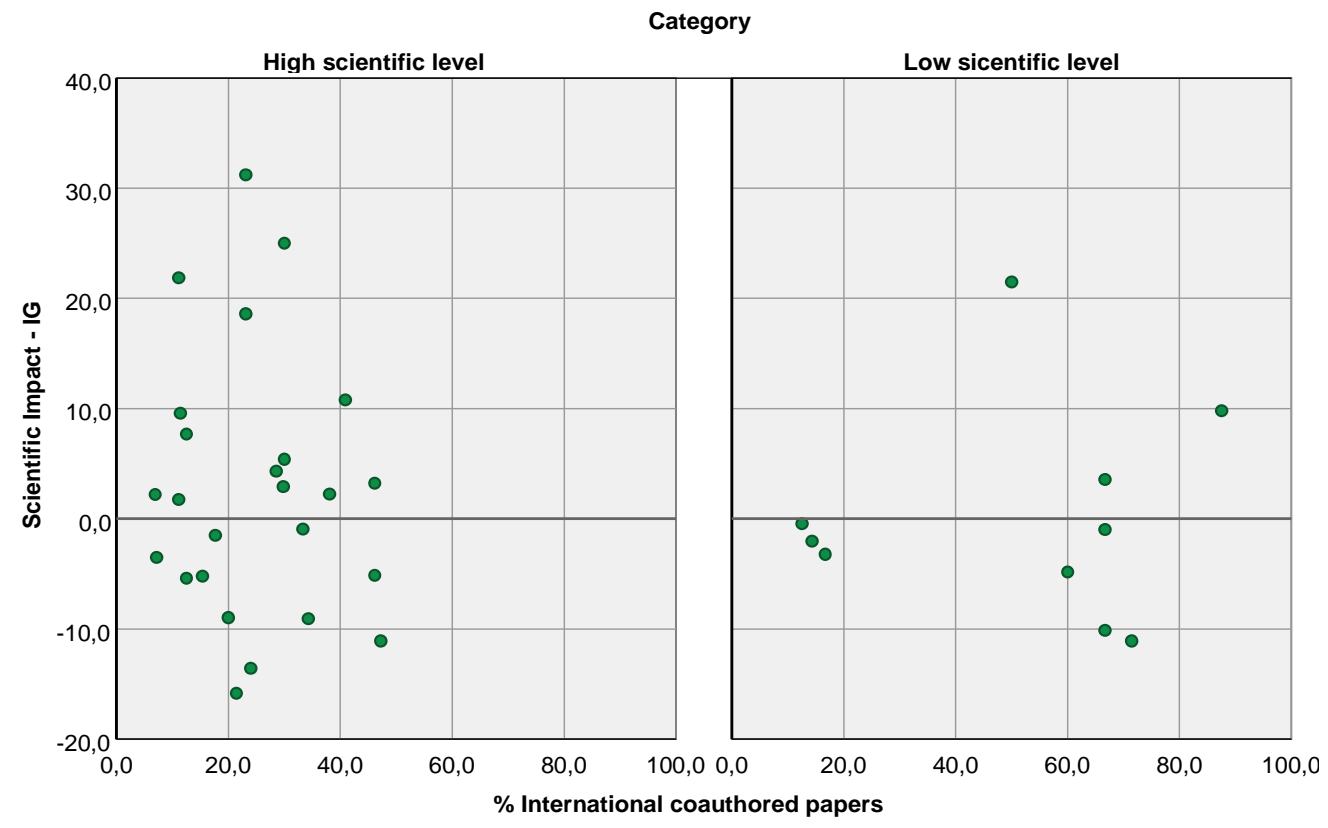

b) Technical Sciences Area

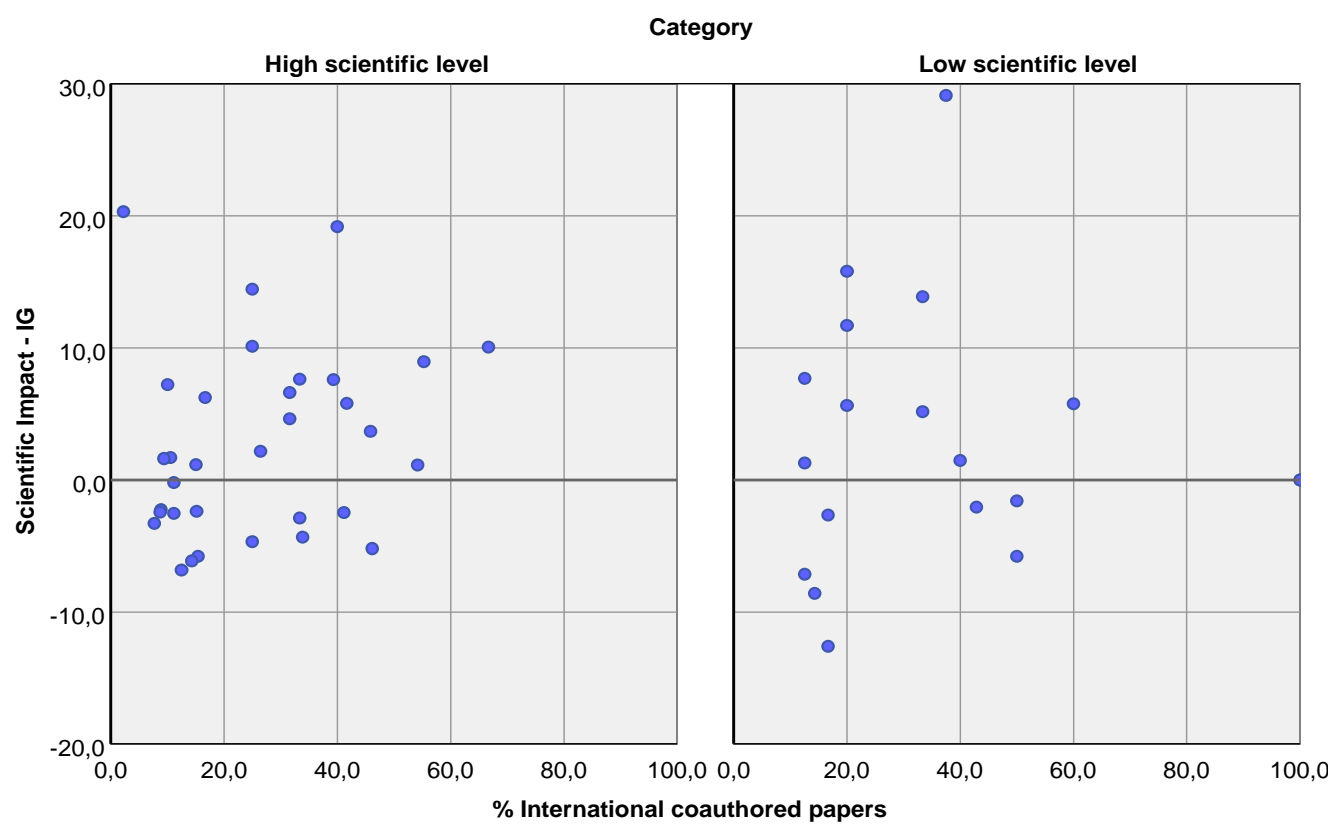




\section{- Gains by the presence of the Inter-sector Collaboration - INSSC}

Figures $3 \mathrm{a}$ and $3 \mathrm{~b}$ display the scientific quality gains versus the percentage of articles produced by involving inter-sector collaboration partners, for each group in every category and scientific area. The results suggest that the groups' production level of ISI articles does not show a clear distinction when gains in scientific quality are estimated due to the presence of INSSC. The gains obtained through this type of collaboration (there is benefit if the Index of Gain IG>0) for groups with high scientific level are more evident in Technical Science groups than in Basic Science groups, although there is no clear evidence that there is a direct relationship between the extension of collaboration and the gains in scientific quality. For the Basic Science groups, the extension of inter-sector collaboration seems to be higher than for the Technical Science groups.

The presence of inter-sector collaboration using their level of contribution to increase the number of citations of ISI articles is also valued. The results in this sense indicate significant gains for groups with a low scientific level, which articles involving inter-sector collaboration widely contribute to the scientific impact level obtained by their publications. In the case of groups with a high scientific level, there are differences as a result of the presence of this type of collaboration. While the Basic Science groups achieve positive gains in a range between 5 and $40 \%$, showing a probability of $29,7 \%$ of being favorable; in the groups of Technical Science, the favorable and unfavorable gains are almost equally likely to occur, and they happened in a range between $-20 \%$ and $30 \%$. Considering the number of groups obtaining benefits from inter-sector collaboration, it is found that the Technical Science groups are more likely to achieve gains when compared with the Basic Science groups $(54,7 \%$ to $48,6 \%$, respectively).

\section{Discussion and limitations}

This article aimed at answering two main questions: a) What are the effects of collaboration in the groups' performance? Are these effects related with the presence of a specific type of collaboration? The results of this study give evidence to believe that the collaboration causes a positive effect on the groups' performance in terms of scientific quality; and this effect, if measured on coauthored ISI articles produced, is dependently on the type of collaboration where its takes place.

The case analyzed in this paper contributes to increase the knowledge about the relation between scientific collaboration and performance, at a non usual micro-level: the academic research groups (ARG). The analysis of the ISI articles coauthored allowed us to characterize them through the geographical and sector dimensions. The initial exercise to characterize the articles under the institutional dimension showed that ISI articles with at least one coauthor, not a member of UPV case of inter-institutional collaboration-, in average were published in journals with a high impact factor and had a higher citation rate. But these favorable conditions found under inter-institutional collaboration can hardly be attributed only to the presence of external coauthors; to these conditions, the corporate image of coauthors' institutions, the novelty of the topic, the particularity of the scientific field could also have contributed. 
Figure 3. Scatter plot between Gains in Scientific Impact and Inter-sector Scientific Collaboration $a=256$ articles, $g=81$ ARG

a) Basic Sciences Area

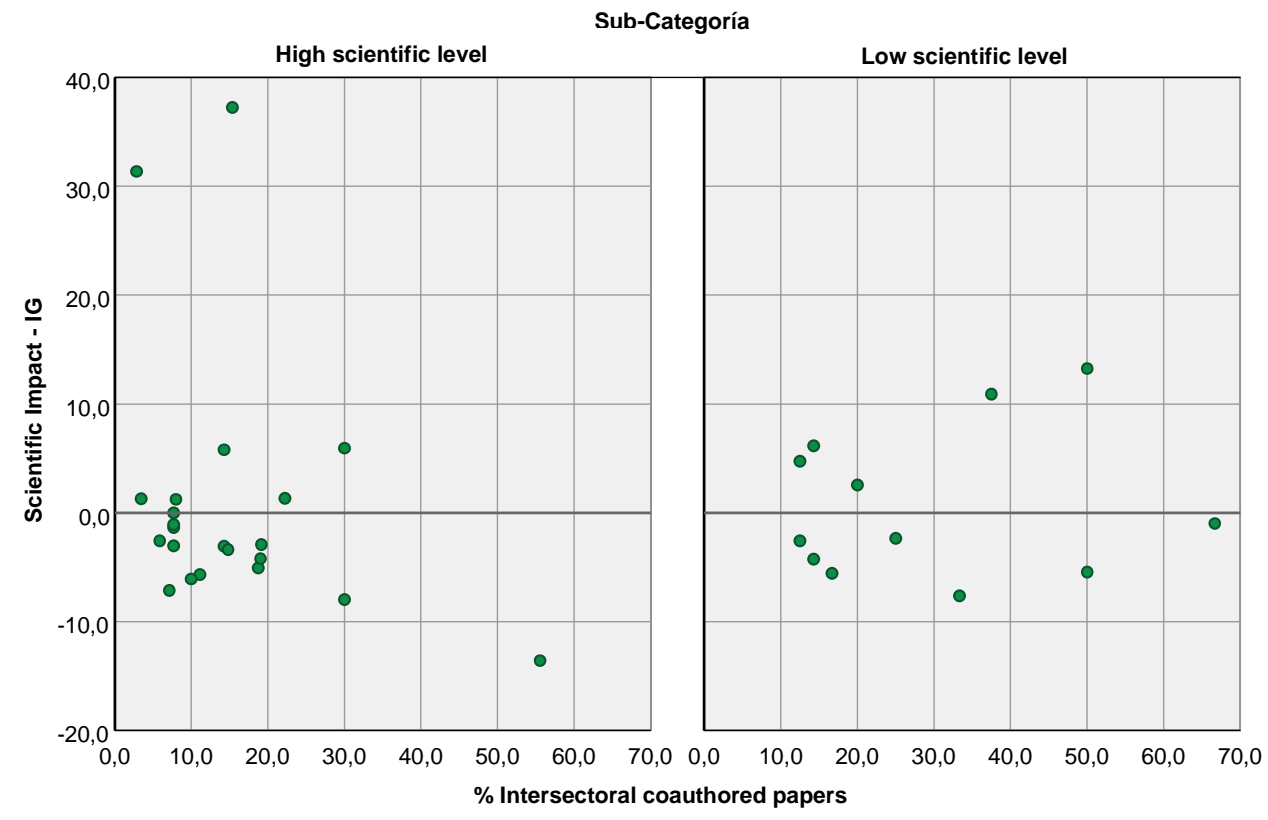

b) Technical Sciences Area

$\mathrm{g}=56$

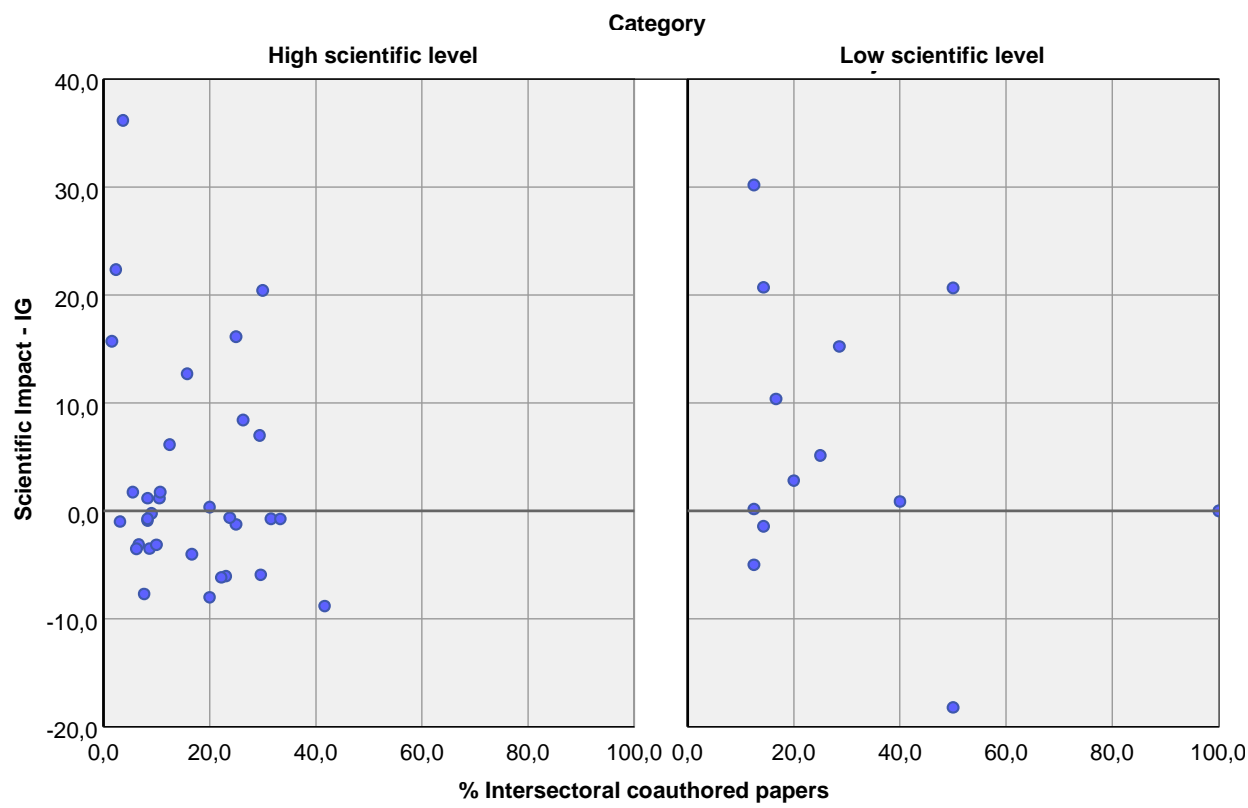


The subsequence analysis of the collaboration gains, distinguishing its presence under geographical and sector dimensions, suggests that into the international collaboration, the inter-institutional one is more clearly related with a higher scientific quality: the groups' articles have higher citation and are published in journals with a high impact. These results are not surprising at all, not only because the presence of international coauthor by itself offers the potential opportunity to articles being divulged in other scientific communities, but also and mainly, because the interaction among coauthors with different knowledge basements, techniques and points of views, opens up new ways of thinking, motives innovative ideas and makes most likely the synergy among the parts, and therefore it increases the possibilities to have publications with high quality and novelty,

The methodological issues taken into an account in this paper, motivates us to think about the limitations of this study. The first limitation is the scope of the results. Since it is supported on the case of research academic groups of a particular university, the results cannot be generalized at all. However, they are worthy to the analyzed University, because more than $80 \%$ of the groups actually working in this University in 2005 , were considered into the sample. Other limitation is the form of measurement. The results are based only on the empirical evidence offered by the scientific articles' co-authorship, under the assumption that results published in coauthored papers were also co-produced in some way by the parts involved. It is known that others researchers have used questionnaires or interviews to reduce the limitations of this kind of measurement and to complement the collaboration analysis with the study of subjective factors that can be correlated like group's culture or researchers' motivation. A third limitation is derived from the study source, ISI articles. However this kind of articles are considered by the international scientific community as one of the most relevant product of the activities made by an academic research group, the truth is that scientific collaboration takes place in other important products of the groups, such as patents and books. A final limitation is produced by the heterogeneity of the sample, because the groups differ in terms of size, age and productivity. Even considering that these differences are quite smoothed with the Index (because it is based on a weighted average), we re-fitted the sample in order to control the effect of outliers groups on the statistics test, and also we ran scatter plots checking that there was not evidence of significant correlations between the endogenous groups' variables and the Indexes of Gain calculated.

\section{Conclusions}

Based on the empirical case analyzed, the conclusion is that scientific collaboration contributes to the performance level of the ARG, especially when the performance is related with the groups' scientific quality. The contribution is evident in the analysis of scientific collaboration that takes place in the ISI articles produced by the groups selected to this study. The analysis of these articles suggest that inter-institutional collaboration is related with the high scientific quality of these publications (measured the quality in terms of impact and relevance), particularly the collaboration that involves international partners, because these articles are more likely to be published in journals having a high international impact and therefore, having greater opportunities to be cited by any researcher around the world. 
Because these findings are supported only in one institutional case study, more research is required before to generalize, that the benefits through scientific collaboration are always present, even considering the particularities of the university in study, or even changing the unit of analysis used in this paper. Here it is worth to mention the recent study of Ordonez (2008), who analyzing a Latin-American country case found that both, the collaboration activity type and the partner type, do matter when explaining the effects of international research collaboration on the work team's performance.

\section{Acknowledgments}

The authors are grateful for the financial support from the Spanish Institute of Knowledge and Innovation Management, INGENIO (CSIC-UPV), as well as for the LANMOT-ALFA Project (UE). This paper is also an extension of the doctoral thesis (and uses material collected in) developed into a research project No. SEJ2005-08603/PSIC named "Influence of organizational culture and knowledge flows on the scientific performance of technological R\&D Groups, Application on the UPV", financed by the National R\&D Plan of the Spanish Ministry of Education and Science.

\section{References}

Abbot J, N Boyd and G Miles (2006). Does type of team matter? An investigation of the relationships between job characteristics and outcomes within a team-based environment. Journal of Social Psychology, 146(4), pp, 485-507.

Basu A and R Aggarwal (2001). International collaboration in science in India and its impact on institutional performance. Scientometrics, 52(3), pp, 379-394.

Beaver D (2001). Reflections on scientific collaboration (and its study): past, present, and future. Scientometrics, 52(3), pp, 365-377.

Belkhodja O and R Landry (2005). The Triple Helix collaboration: Why do researchers collaborate with industry and government? What are the factors influencing the perceived barriers? In 5th Triple Helix Conference, Turin, Italia.

Bowman E and D Hurry (1993). Strategy through the options lent: an integrated view of resource investments and the incremental-choice process. Academic of management review, 18(4).

Bozeman B and S Lee (2003). The impact of research collaboration on scientific productivity. In Annual meeting of the American Association for the Advancement of Science,Denver, Colorado.

Bozeman B and E Corley (2004). Scientists' collaboration strategies: implications for scientific and technical human capital. Research Policy, 33, pp, 599-616.

Dodgson M (1999). What role for management in Science? Technology Analysis \& Strategic Management, 11(2).

Ebers M and J Jarillo (1998). The construction, forms and consequences of industry networks, International Studies of Management and Organization, 27(14), pp, 3-21.

Etzkowitz H and L Leydesdorff (2000). The dynamics of innovation: from National Systems and 'Mode-2' to a Triple Helix of university-industry-government relations. Research Policy, 29(2), pp, 109-123.

Gibbons M, H Nowonthy, C Limoges, S Schwartzman and P Scott (1994). The new production of Knowledge. London: Sage.

Glänzel W and A Schubert (2005). Domesticity and internationality in co-authorship, references and citations. Scientometrics, 65(3), pp, 323-342.

Guimerá R, B Uzzi, J Spiro and L Nunez (2005). Team assembly mechanisms determine collaboration network structure and team performance. Science, 308(29), pp, 697-702. 
Hagedoorn J, A Links and N Vonortas (2000). Research partnership. Research Policy, 29(4-5), pp, 567-586.

Havemann F, M Heinz, and H Kretschmer (2006). Collaboration and distances between German immunological institutes - A trend analysis. Journal of Biomedical Discovery and Collaboration, 1(6).

Hemphill T and N Vonortas (2003). Strategic research partnership: a managerial perspective. Technology Analysis and Strategic Management, 15(2).

Kogut B (1988). Joint ventures: theoretical and empirical perspectives. Strategic Management Journal, 9(4), pp, 319-332.

Lowrie A and P McKnight (2004)- Academic research networks: a key to enhancing scholar standing. European Management Journal, 22(4), pp, 345-360.

Luo J (2005). Social networks structure and performance of improvements teams. International Journal Business Performance Management, 7(2), pp, 208-223.

Melin G, (2000). Pragmatism and self-organization research collaboration on the individual level. Research Policy, 29, pp, 31-40.

Ordonez-Matamoro G (2008). International collaboration, research team performance, and scientific \& technological capabilities in Colombia - A bottom-up perspective. Doctoral thesis, Join Program of the School of Public Policy and the Andrew Young School of Policy Studies. Georgia State University \& Georgia State University.

Rigby J (2005). Handcrafted by 16 men: the impact of single and multiple authorship in collaborative research networks. Research Evaluation, 14(3), pp, 199-206.

Rogers J (2000). Theoretical consideration of collaboration in scientific research, Chap. 6. In Strategies for competitiveness in academic research. S Hauger and C McEnaney (Eds). American Association for the Advancement of Science, pp, 151-177. Available at 〈www,aaas,org/spp/rcp >, last accessed 20 January 2007.

Smith D and J Katz (2000). HEFCE Fundamental review of research policy and funding, Collaborative Approaches to Research. Higher Education Policy Unit (HEPU), University of Leeds and Science Policy Research Unit (SPRU), University of Sussex.

Sigogneau A, O Malagutti, M Crance and S Bauin (2005). Cross-disciplinary research: co-evaluation and copublication practices of the CNRS laboratories. Research evaluation, 14(2), pp, 165-176.

Veugelers R, (2000). Collaboration in R\&D: an assessment of theoretical and empirical findings. FETEW Catholieke Universiteit of Leuven, Leuven (Belgium). 